\title{
Epidemiology, treatment and mortality of trochanteric and subtrochanteric hip fractures: data from the Swedish fracture register
}

Leif Mattisson ${ }^{1 *}$, Alicja Bojan ${ }^{2}$ and Anders Enocson ${ }^{1,3}$

\begin{abstract}
Background: Hip fractures are a major worldwide public health problem and includes two main types of fractures: the intracapsular (cervical) and the extracapsular (trochanteric and subtrochanteric) fractures. The aim of this study on patients with trochanteric and subtrochanteric hip fractures was to describe the epidemiology, treatment and outcome in terms of mortality within the context of a large register study.

Methods: A descriptive epidemiological register study including patients registered in the national Swedish Fracture Register from January 2014 to December 2016. Inclusion criteria were all primary surgically treated traumatic nonpathological trochanteric and subtrochanteric femoral fractures in patients aged 18 years and above. Individual patient data (age, gender, injury location, injury cause, fracture type, treatment and timing of surgery) were retrieved from the register database. Mortality data was obtained via linkage to the Swedish Death Register.

Results: A total of 10,548 consecutive patients were identified and included in the study. The mean ( \pm SD) age for all patients was $82 \pm 11$ years and the majority of the patients were females (69\%). Most of the fractures were caused by a fall at the same level (83\%) at the patients' accommodation (75\%). Fractures were classified using the AO/OTA classification as $31-\mathrm{A} 1$ in $29 \%$, as $31-\mathrm{A} 2$ in $49 \%$ and as $31-\mathrm{A} 3$ in $22 \%$ of the cases. The most commonly used implant was a short antegrade intramedullary nail (42\%), followed by a plate with sliding hip screw (37\%). With increasing fracture complexity, the proportion of intramedullary nails was increasing, and also the use of long versus short nails. The majority of the patients were operated within $36 \mathrm{~h}$ (90\%). There was a higher mortality at 30 days and 1 year for males, and for all those who were delayed to surgery $>36 \mathrm{~h}$.
\end{abstract}

Conclusion: Safety measures to prevent fall at elderly patient's accommodation might be a way to reduce the number of trochanteric and subtrochanteric hip fractures. Surgery as soon as possible without delay should be considered to reduce the mortality rate. The selection of surgical methods depends on the fracture complexity.

Keywords: Hip fracture, Trochanteric fracture, Surgical treatment, Epidemiology, Register study

\footnotetext{
* Correspondence: leif.mattisson@sll.se

${ }^{1}$ Department of Clinical Science and Education, Södersjukhuset, Karolinska Institutet. Department of Orthopaedics, Stockholm South General Hospital, 11883 Stockholm, Sweden

Full list of author information is available at the end of the article
}

(c) The Author(s). 2018 Open Access This article is distributed under the terms of the Creative Commons Attribution 4.0 International License (http://creativecommons.org/licenses/by/4.0/), which permits unrestricted use, distribution, and reproduction in any medium, provided you give appropriate credit to the original author(s) and the source, provide a link to the Creative Commons license, and indicate if changes were made. The Creative Commons Public Domain Dedication waiver (http://creativecommons.org/publicdomain/zero/1.0/) applies to the data made available in this article, unless otherwise stated. 


\section{Background}

Hip fractures are a major public health problem and can lead to disability, reduced quality of life and increased mortality. Hip fractures in general are affecting around 1.5 million people per year worldwide, with the highest rates found in Scandinavia and the lowest in Africa [1, 2]. The number of hip fractures is likely to increase as the number of elderly people is increasing and worldwide it has been estimated that the number of hip fractures will rise to 2.6 million by 2025, and to 6.25 million in 2050 [1, 3]. The hip fractures are a heterogenous group with two main types of fractures: the intracapsular (cervical) and the extracapsular (trochanteric and subtrochanteric) fractures.

The absolute majority of the trochanteric and subtrochanteric hip fracture patients are fragile patients with a tendency to fall and an increased risk of major morbidity and mortality [4-7]. It is important to provide adequate management to these patients and the treatment of choice is normally surgical with internal fixation. The surgical options for these fractures commonly include plating with sliding hip screw or intramedullary nailing, with nailing today being the predominant procedure in many parts of the world $[8,9]$.

Although most of the authors in the literature recommend that hip fracture patients should be operated without delay to allow early mobilization and thereby reducing mortality and morbidity, the topic is still controversial and the effect of the time to surgery on mortality is debated [10-13].

The Swedish Fracture Register (SFR) is a nationwide register in which data on fracture epidemiology is reported. Previous publications from the register on specific fractures includes humeral and clavicle fractures $[14,15]$.

The aim of this study on patients with trochanteric and subtrochanteric hip fractures was to describe the epidemiology, treatment and outcome in terms of mortality within the context of a large register study.

\section{Methods}

The SFR started in 2011 and collects information on fractures in extremities, pelvis and spine. The database is national and the data is registered locally at the affiliated departments. Detailed data on fracture epidemiology and treatment is registered and all fractures are registered regardless of treatment type - surgical or non-surgical. To be included in the register the patients need to have a permanent Swedish personal identity number and only fractures that have occurred in Sweden are registered. At the start of this study in January 2014 the number of affiliated departments was 24, and end of the study in December 2016 the number of affiliated departments was 39. The total number of departments in Sweden that are treating fractures is estimated to 54. Data on patient mortality is obtained to the register via linkage to the national Swedish Death Register.
Inclusion criteria in this study were primary surgically treated traumatic non-pathological trochanteric and subtrochanteric femoral fractures in patients aged 18 years and above, occurring from January 2014 to December 2016.

\section{Variables}

Epidemiologic data (patient age and gender), injury data (injury location, cause and date), fracture data (fracture type, treatment and timing of surgery) and mortality data were retrieved from the register database.

Injury location was categorized as: at the patients' residence or accommodation, in a public place, in a street/ road or in an unspecified place. The cause of injury was divided into: a fall at the same level, an unspecified fall, a fall from height, a traffic injury or any other cause. There is no strict guideline for classification of the energy level in the SFR, and it is up to the registering doctor to distinguish between high- and low-energy trauma mechanism. Fractures were classified according to the AO/OTA classification [16] and the ICD-10 code. Surgical implants were categorized as: a short or long antegrade intramedullary nail, a retrograde intramedullary nail, a plate with sliding hip screw, any other type of plate fixation, a hip arthroplasty or any other type of implant. The experience of the main surgeon was divided into: a specialist in orthopaedic surgery, an orthopaedic registrar or any other surgeon. Starting in early 2015, the time of the radiograph confirming the fracture and the time of the start of the operation was included in the register. From these variables, the time (in hours) from the radiograph to the start of the surgery was calculated.

Patient mortality was presented as 30-day and 1-year mortality.

\section{Statistics}

Because of the descriptive nature of the study, statistical testing of the variables was not performed. Variables are presented as proportions of all registered fractures, meaning the available number of inputs in the register excluding any missing values. For scale variables mean \pm standard deviations (SD) are presented. The statistical software used was IBM SPSS Statistics, Version 23 for Windows (SPSS Inc., Chicago, USA).

\section{Results}

\section{Patient and fracture epidemiology}

A total of 10,548 entries fulfilling the inclusion criteria were identified in the register and included in the study. The majority of the patients were female $(69.4 \%, n=$ $7317 / 10548)$ and the mean $( \pm S D)$ age for all patients was $82.4 \pm 10.5$ years. The mean $( \pm \mathrm{SD})$ age was higher for females $(83.9 \pm 9.1$ years) compared to males $(78.9 \pm$ 12.3 years) (Fig. 1 ). 


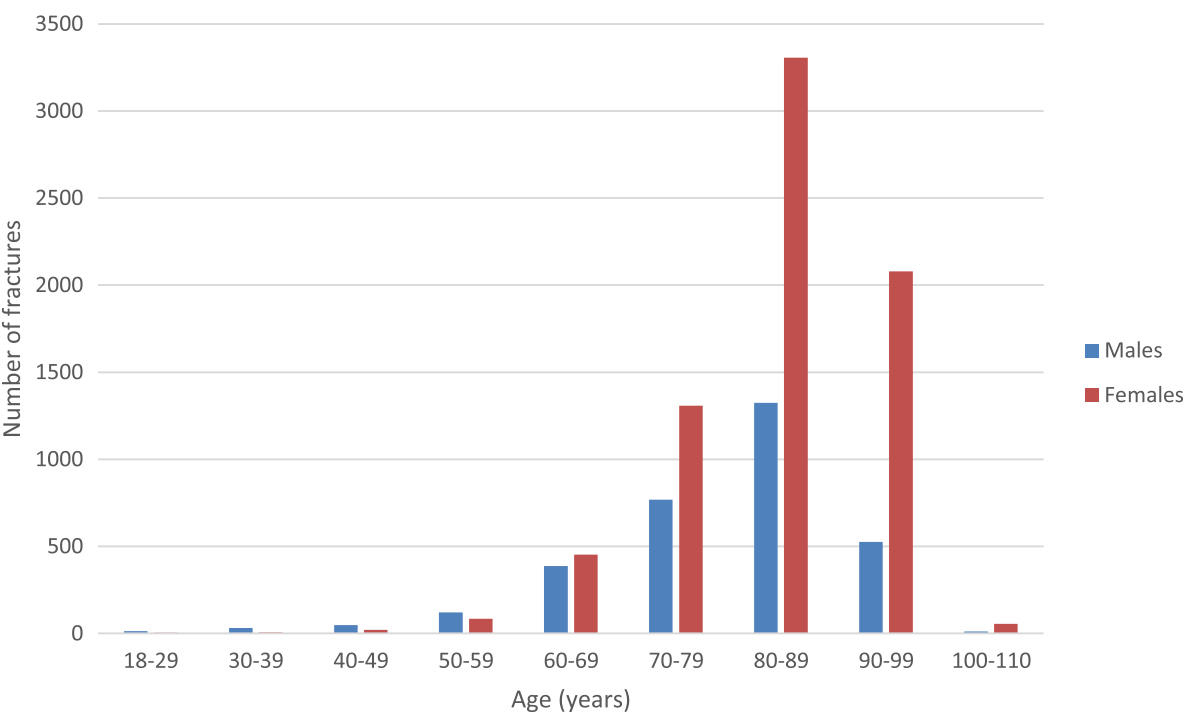

Fig. 1 Distribution of trochanteric and subtrochanteric femoral fractures by age and gender

The location for the trauma was at the patients' current residence or accommodation in 75\% $(n=7631 /$ 10249) of the cases, in a public place in $4.1 \%(n=418 /$ $10249)$, in a street/road in $3.7 \%(n=378 / 10249)$ or in an unspecified place in $18 \%(n=1822 / 10249)$. The cause of the injury was a fall at the same level $(83 \%, n=8796$ / $10548)$, an unspecified fall $(9.8 \%, n=1034 / 10548)$, a fall from height $(4.0 \%, n=420 / 10548)$, a traffic injury $(2.0 \%$, $n=212 / 10548)$ or any other cause $(0.8 \%, n=86 / 10548)$. Fractures were most common during the winter months of January and December (Fig. 2).

The fractures were classified according to the ICD-10 code system as trochanteric (S72.1) in 78\% $(n=8260$ / 10548) and as subtrochanteric (S72.2) in 22\% $(n=2288$ / 10548 ) of the cases. In addition, fractures were classified using the AO/OTA classification as $31-\mathrm{A} 1$ in $29 \%$
( $n=3067 / 10546)$, as $31-\mathrm{A} 2$ in $49 \%(n=5191 / 10546)$ and as $31-\mathrm{A} 3$ in $22 \%(n=2288 / 10546)$ of the cases (Fig. 3). The fractured side was equally distributed with $50 \%(n=$ $5253 / 10548)$ involving the right side and 50\% $(n=5295 /$ 10548) involving the left side. Fourteen patients (out of $10,548,0.1 \%)$ had an open fracture and $1.6 \%(n=169 /$ 10246) of the fractures were due to a high-energy trauma. Patient and injury epidemiology data in relation to fracture type are presented in Table 1.

\section{Surgical results}

The majority of the patients were operated within $24 \mathrm{~h}$ ( $75 \%, n=4471 / 5928)$, or $36 \mathrm{~h}(90 \%, n=5354 / 5928)$ from time of the radiograph verifying the fracture to the start of the operation. The operations were performed during night time $(22-08 \mathrm{~h})$ in $8.5 \%(n=522 / 6126)$ of the cases. The

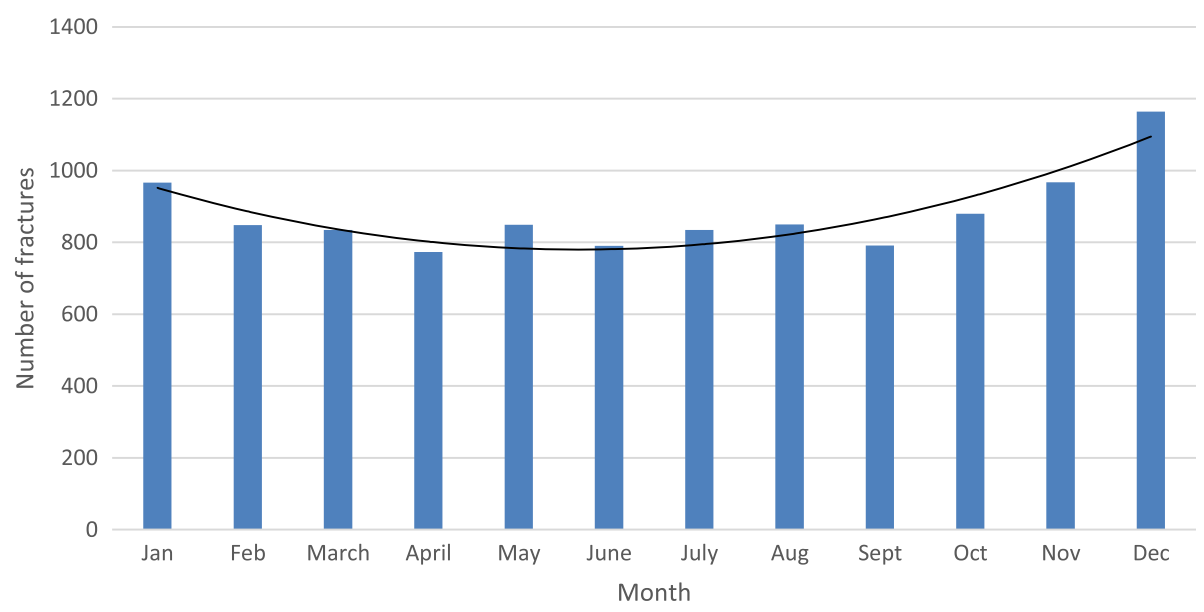

Fig. 2 Monthly distribution of trochanteric and subtrochanteric femoral fractures 


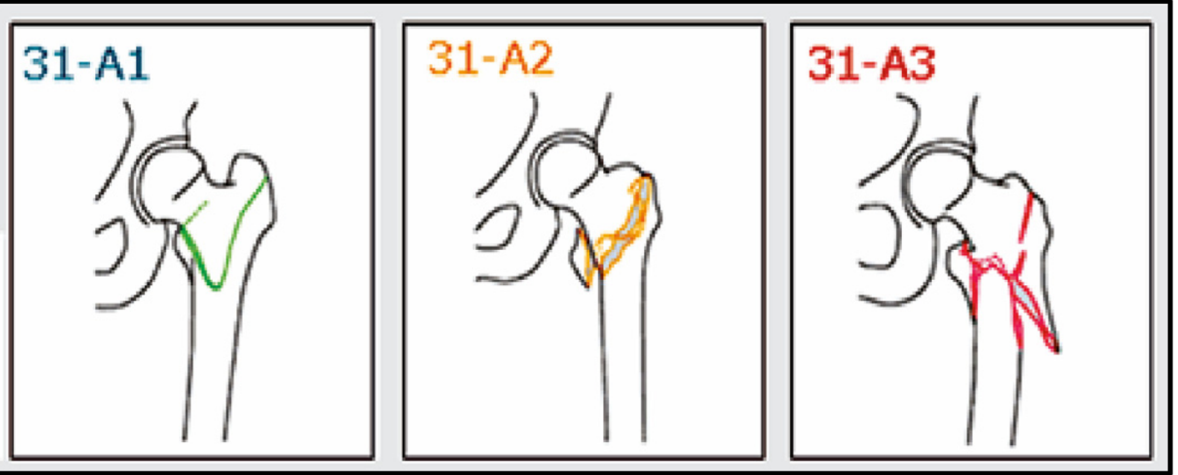

Fig. 3 Fracture groups as presented in the SFR. According to AO/OTA classification of trochanteric and subtrochanteric femoral fractures. The use of the figure in this study has been approved by the SFR: 31-A1 Simple trochanteric fractures. 31-A2 Multifragmented trochanteric fractures. 31-A3 Trochanteric reverse oblique and subtrochanteric fractures.

operations were performed by a specialist in orthopaedic surgery in $62 \%(n=6348 / 10186)$, an orthopaedic registrar in $37 \%(n=3759 / 10186)$ or by any other surgeon in $0.8 \%$ $(n=79 / 10186)$ of the cases. Implants used were: a short antegrade intramedullary nail (42\%, $n=4411 / 10548)$, a plate with sliding hip screw $(37 \%, n=3935 / 10548)$, a long

Table 1 Overview of patient and injury epidemiology in relation to fracture type ${ }^{a}$

\begin{tabular}{llll}
\hline & $\begin{array}{l}31-\mathrm{A} 1 \\
(n=3067)\end{array}$ & $\begin{array}{l}31-\mathrm{A} 2 \\
(n=5191)\end{array}$ & $\begin{array}{l}31-\mathrm{A} 3 \\
(n=2288)\end{array}$ \\
\hline $\begin{array}{l}\text { Age years, mean }( \pm \mathrm{SD}) \\
\%(n=)\end{array}$ & $82.2(10.3)$ & $83.2(9.8)$ & $81.0(12.0)$ \\
Female gender & $65(1981 / 3067)$ & $72(3725 / 5191)$ & $70(1610 / 2288)$ \\
Injury location & & & \\
At residence & $74(2202 / 2960)$ & $75(3816 / 5069)$ & $73(1611 / 2218)$ \\
Public place & $4.8(143 / 2960)$ & $4.6(233 / 5069)$ & $4.4(97 / 2218)$ \\
Street/road & $3.5(103 / 2960)$ & $3.6(183 / 5069)$ & $4.1(92 / 2218)$ \\
Other & $17(512 / 2960)$ & $17(837 / 5069)$ & $19(418 / 2218)$ \\
Injury mechanism & & & \\
Fall at same level & $84(2561 / 3067)$ & $84(4363 / 5191)$ & $82(1870 / 2288)$ \\
Unspecified fall & $9.7(299 / 3067)$ & $10(532 / 5191)$ & $8.9(203 / 2288)$ \\
Fall from height & $3.6(111 / 3067)$ & $3.4(179 / 5191)$ & $5.7(130 / 2288)$ \\
Traffic & $2.4(74 / 3067)$ & $1.7(87 / 5191)$ & $2.2(51 / 2288)$ \\
Other & $0.7(22 / 3067)$ & $0.6(30 / 5191)$ & $1.5(34 / 2288)$ \\
High energy trauma & & & $1.1(55 / 5045)$
\end{tabular}

Data is presented in relation to the number of available inputs in the register ${ }^{a}$ Fracture type according to the AO/OTA classification:

31-A1 Simple trochanteric fractures

31-A2 Multifragmented trochanteric fractures

31-A3 Trochanteric reverse oblique and subtrochanteric fractures antegrade intramedullary nail $(18 \%, n=1903 / 10548)$, any other type of plate fixation $(1.6 \%, n=167 / 10548)$, a retrograde intramedullary nail $(0.6 \%, n=63 / 10548)$, a hip arthroplasty $(0.5 \%, n=58 / 10548)$ or other implants $(0.1 \%$, $n=11 / 10548)$. Implants used in relation to fracture type are presented in Fig. 4.

\section{Mortality}

The overall 30-day mortality was $7.7 \%(n=811 / 10548)$ and the 1 -year mortality was $26 \%(n=2731 / 10548)$. There was a higher 30 -day mortality for males $(11 \%, n=355$ / $3231)$ compared to females $(6.2 \%, n=456 / 7317)$. As was there a higher 1 -year mortality for males $(32 \%, n=1026$ / $3231)$ compared to females (23\%, $n=1705 / 7317)$. One-year mortality for different age-groups is presented in Fig. 5. The 30-day mortality was higher for patients operated $>36 \mathrm{~h}(9.8 \%, n=56 / 574)$ compared to patients operated $\leq 24 \mathrm{~h}(7.8 \%, n=349 / 4471)$ or $\leq 36 \mathrm{~h}(8.0 \%, n=429 /$ 5354). Operations delayed for surgery $>36 \mathrm{~h}$ also had a higher 1 -year mortality $(31 \%, n=179 / 574)$ compared to operations performed $\leq 24 \mathrm{~h}(25 \%, n=1118 / 4471)$ or $\leq 36 \mathrm{~h}(26 \%, n=1370 / 5354)$. Detailed results on mortality are presented in Table 2.

\section{Discussion}

In this observational study of trochanteric and subtrochanteric hip fractures in Sweden during the years 2014 to 2016 the majority of the patients were women (69\%) with a high mean age (84 years) and a fracture caused by a fall at the same level at their accommodation. The most common type of fracture according to the $\mathrm{AO} /$ OTA classification was a type 31-A2 and the majority of the patients were operated with a short intramedullary nail within $36 \mathrm{~h}$. There was a higher mortality at 30 days and 1 year for males, and for all those who were delayed to surgery $>36 \mathrm{~h}$. 


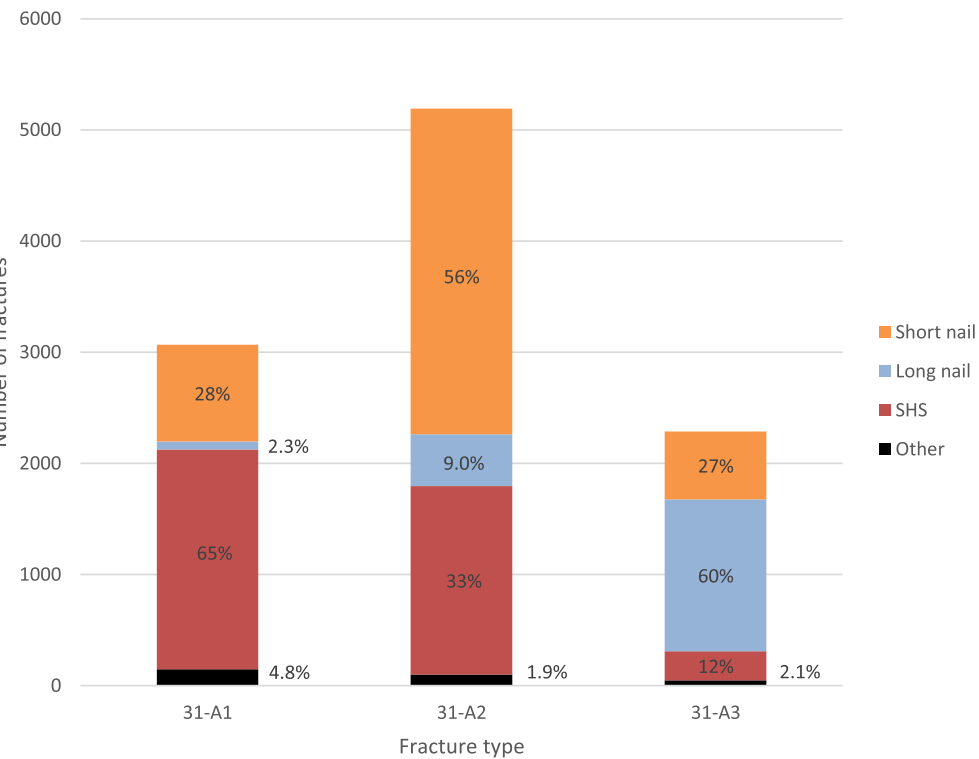

Fig. 4 Fracture type according to the AO/OTA classification in relation to treatment

\section{Epidemiology}

Our finding of a higher number of fractures among females is in line with most of the previous studies and has an association with osteoporosis [4, 17-21]. The high age of the patients reflects that there is an increased risk to fall with advanced age, and as these patients often are frail with poor bone-quality there is an increased risk for suffering from a hip fracture even after a low energy fall. Mangram et al. 2014 [17] described that 73\% of their trochanteric fracture patients fell at home. Similarly, Haginoa et al. 2017 [6] reported that an indoors simple fall was the trauma mechanism in $80 \%$ of their hip fracture patients, and $85 \%$ of them were $\geq 90$ years old. Interestingly we found that fractures were slightly more common during the winter months of January and December, despite that the majority of them occurred indoors at the patients' accommodation. But this finding is in line with previous studies. Pueyo-Sanchez et al. 2017 [22] reported that in Catalonia, Spain a seasonal variation was observed with more cases in the winter. Similarly, Gronskag et al. 2010 [23] found a seasonal variation in hip fracture incidence among elderly women in Norway, which was characterized by higher fracture rates during the winter months. Finally, Hagino et al. 2017 [6] reported a monthly variation were January had the highest number of patients per month during the observation period.

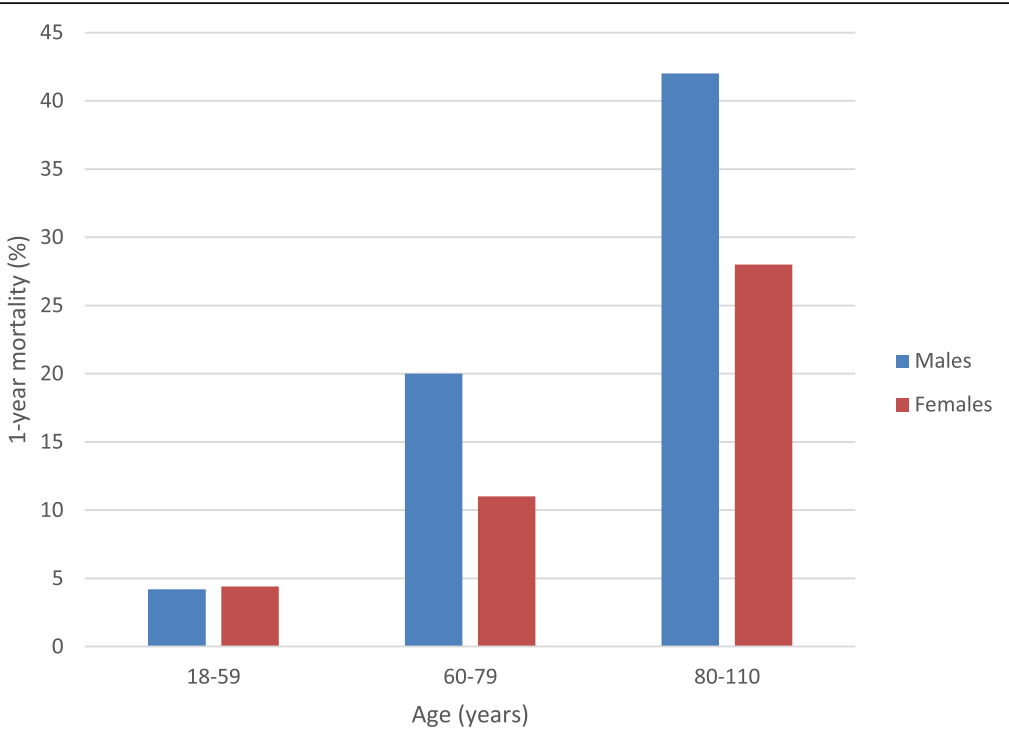

Fig. 5 Comparison of 1-year mortality between males and females for different age-groups 
Table 2 Mortality in relation to gender, fracture type and surgical factors

\begin{tabular}{|c|c|c|}
\hline & $\begin{array}{l}\text { 30-day mortality } \\
\%(n=)\end{array}$ & $\begin{array}{l}\text { 1-year mortality } \\
\%(n=)\end{array}$ \\
\hline All & $7.7(811 / 10548)$ & $26(2731 / 10548)$ \\
\hline \multicolumn{3}{|l|}{ Gender } \\
\hline Female & $6.2(456 / 7317)$ & $23(1705 / 7317)$ \\
\hline Male & $11(355 / 3231)$ & $32(1026 / 3231)$ \\
\hline \multicolumn{3}{|l|}{ Fracture type $\mathrm{a}^{\mathrm{a}}$} \\
\hline $31-A 1$ & $7.2(222 / 3067)$ & $26(793 / 3067)$ \\
\hline $31-A 2$ & $8.2(427 / 5191)$ & $27(1389 / 5191)$ \\
\hline $31-\mathrm{A} 3$ & $7.1(162 / 228)$ & $24(548 / 2288)$ \\
\hline \multicolumn{3}{|l|}{ Time to surgery } \\
\hline$\leq 24 \mathrm{~h}$ & $7.8(349 / 4471)$ & $25(1118 / 4471)$ \\
\hline$\leq 36 \mathrm{~h}$ & $8.0(429 / 5354)$ & $26(1370 / 5354)$ \\
\hline$>36 \mathrm{~h}$ & $9.8(56 / 574)$ & $31(179 / 574)$ \\
\hline \multicolumn{3}{|l|}{ Time of surgery start } \\
\hline $08-22$ & $8.2(460 / 5604)$ & $26(1476 / 5604)$ \\
\hline $22-08$ & $8.0(42 / 522)$ & $24(126 / 522)$ \\
\hline \multicolumn{3}{|l|}{ Implant } \\
\hline Short intramedullary nail & $8.2(362 / 4411)$ & $27(1167 / 4411)$ \\
\hline Long intramedullary nail & $6.8(130 / 1903)$ & $24(450 / 1903)$ \\
\hline Plate with sliding hip screw & $7.6(298 / 3935)$ & $26(1030 / 3935)$ \\
\hline Other & $7.0(21 / 299)$ & $28(84 / 299)$ \\
\hline
\end{tabular}

Data is presented in relation to the number of available inputs in the register ${ }^{a}$ Fracture type according to the AO/OTA classification:

31-A1 Simple trochanteric fractures

31-A2 Multifragmented trochanteric fractures

31-A3 Trochanteric reverse oblique and subtrochanteric fractures

\section{Fracture and treatment characteristics}

We found that the AO/OTA type 31-A1 and 31-A2 fractures, which are sometimes referred to as stable, were most common (78\%). This finding is similar to Chehade et al. [20] who in 2015 published a prospective consecutive cohort of 743 patients were the majority (60\%) were classified as stable trochanteric and only $40 \%$ as unstable trochanteric or subtrochanteric fractures. We found that with increasing fracture complexity, the proportion of intramedullary nails was increasing, and also the use of long versus short nails. Previous literature have advocated superiority of intramedullary nails, compared to plate with sliding hip screw, and proposed advantages in the management of unstable trochanteric and subtrochanteric fractures in providing biomechanical stability and improved functional outcome [8, 9, 24-27]. Furthermore, a long nail can offer protection all along the femur, in comparison to a short nail [28-30]. In our observational study we found that although intramedullary nailing was the most commonly used implant overall, the plate with sliding hip screw was commonly used as well, especially for the AO/OTA type 31-A1 fractures (Fig. 4). The "plate versus nail" debate is probably not yet over as the latest Cochrane report comparing intramedullary nails with plate and sliding hip screw concluded that "sliding hip screw appears superior for trochanteric fractures" [31].

\section{Mortality}

We found a higher mortality rate in males, despite younger mean age. As a comparison, the expected 1-year mortality for an unselected population of 80 years old in Sweden 2017 was $3.5 \%$ for females and $4.8 \%$ for males (www.statistikdatabasen.scb.se). In 2010 Kannegaard et al. [32] observed in a nationwide register-based cohort study including more than 41,000 Danish hip fracture patients, increased 1-year mortality in men and that the mean survival time was slightly shorter after trochanteric and subtrochanteric fracture (3.3-3.4 years) compared with other types of hip fractures (3.5-3.8 years). Haentjens et al. [33] performed time-to-event meta-analyses and showed that the relative hazard for all-cause mortality in the first 3 months after a hip fracture was 5.75 in women and 7.95 in men. The majority of our population was operated within $24 \mathrm{~h}(75 \%)$ or 36 h $(90 \%)$ calculated from the time of the radiograph verifying the fracture to the start of the operation. This is consistent with the current recommendations for the management of hip fractures in many settings, although we still lack an international consensus. Obviously, several factors can affect the postoperative mortality, but the time to surgery is one of the most debated ones. Moja et al. 2012 [34] described in a meta-analysis that a delay to surgery was associated with a significant increase in the risk of death and pressure sores, and recommended that most patients with a hip fracture should be operated within 1 or 2 days. In addition, early fracture fixation and mobilization of these patients decreases the economic burden as it might reduce the overall length of stay, and thus the total cost [35]. On the contrary, a recent prospective cohort study from Lizaur-Utrilla et al. 2018 including 1234 patients who underwent hip fracture surgery suggested that waiting time for the surgery more than 2 days to stabilize patients with active comorbidities at admission was not associated with higher complication or mortality rate. However, the patients who were delayed to surgery due to organizational reasons had a significant higher rate of postoperative complications and 1-year mortality [36]. To be able to operate patients within 24 or $36 \mathrm{~h}$ one might need to operate also at nighttime (22:00-8:00 h). We found no relation between mortality and the starting time of the surgery, whether it was performed during daytime or nighttime. Although other studies have defined the nighttime slightly different (16:00-07:00 h) they showed similar results [37, 38]. 


\section{Strengths of the study}

The major strength of this study is the large number of included fractures. The data from the SFR provides prospective data on a national level regardless of local differences in epidemiology, socio-demographics and treatment traditions. The included data is detailed and the register have been well validated [39-41]. Another strength is the mortality data that provides a unique opportunity to integrate epidemiologic data with a relevant outcome measurement.

\section{Limitations of the study}

The SFRs coverage during the study period (January 2014 to December 2016) included with increasing number of participating departments by the end of 2016 approximately only $72 \%$ of Sweden's orthopaedic departments. However, the remaining clinics that have not yet signed up are mostly smaller units, so in reality the national proportion of excluded fractures is most likely small, but still the incomplete coverage of the SFR as a limitation. Registration of the time for the radiograph confirming the fracture and the start of the operation did not start until 2015. The number of valid inputs in the register on this topic is therefore somewhat limited, but since the total number of valid inputs is large, we still think that the results regarding delay to surgery and timing of the operations are valid indicators and represents true national trends. Another limitation is that due to the descriptive nature of this register study all the results were unadjusted regarding different reasons for delay to surgery, implant choice or co-morbidities of the patients.

\section{Conclusion}

Safety measures to prevent fall at elderly patient's accommodation might be a way to reduce the number of trochanteric and subtrochanteric hip fractures. Surgery as soon as possible without delay should be considered to reduce the mortality rate. The selection of surgical methods depends on the fracture complexity.

\section{Abbreviations}

AO: Arbeitsgemeinschaft fur Osteosynthesefragen; OTA: Orthopaedic Trauma Association; SFR: Swedish Fracture Register

\section{Acknowledgements}

The authors wish to thank Michael Möller, director of the SFR, for valuable contribution.

\section{Availability of data and materials}

The datasets used and/or analyzed during the current study are available from the corresponding author on reasonable request.

\section{Authors' contributions}

$L M, A E$ : study design and planning. Data analysis. Writing of the manuscript AB: data collection, data analysis and writing of the manuscript. All authors have read and approved the final manuscript.

\section{Ethics approval and consent to participate}

The study was performed according to the Helsinki declaration and approved by the Regional Ethics Committee in Stockholm (ref number 2018/204-31) at 21 February 2018. Informed consent was waived because of the retrospective design of this study that did not involve any additional risk for patients.

Consent for publication

Not applicable.

\section{Competing interests}

The authors declare that they have no competing interests.

\section{Publisher's Note}

Springer Nature remains neutral with regard to jurisdictional claims in published maps and institutional affiliations.

\section{Author details}

${ }^{1}$ Department of Clinical Science and Education, Södersjukhuset, Karolinska Institutet. Department of Orthopaedics, Stockholm South General Hospital, 11883 Stockholm, Sweden. ${ }^{2}$ Department of Orthopaedics, Sahlgrenska University Hospital Gothenburg/Mölndal, 43180 Mölndal, Sweden.

${ }^{3}$ Department of Molecular Medicine and Surgery, Karolinska University Hospital, Karolinska Institutet, 17176 Stockholm, Sweden.

Received: 28 June 2018 Accepted: 24 September 2018

Published online: 12 October 2018

\section{References}

1. Cooper C, Campion G, Melton LJ 3rd. Hip fractures in the elderly: a worldwide projection. Osteoporos Int. 1992;2(6):285-9.

2. Cheng SY, Levy AR, Lefaivre KA, Guy P, Kuramoto L, Sobolev B. Geographic trends in incidence of hip fractures: a comprehensive literature review. Osteoporos Int. 2011;22(10):2575-86.

3. Gullberg B, Johnell O, Kanis JA. World-wide projections for hip fracture. Osteoporos Int. 1997:7(5):407-13.

4. Brunner LC, Eshilian-Oates L, Kuo TY. Hip fractures in adults. Am Fam Physician. 2003:67(3):537-42.

5. Endo Y, Aharonoff GB, Zuckerman JD, Egol KA, Koval KJ. Gender differences in patients with hip fracture: a greater risk of morbidity and mortality in men. J Orthop Trauma. 2005;19(1):29-35.

6. Hagino H, Endo N, Harada A, Iwamoto J, Mashiba T, Mori S, et al. Survey of hip fractures in Japan: recent trends in prevalence and treatment. J Orthop Sci. 2017;22(5):909-14.

7. Matsuo M, Yamagami T, Higuchi A. Impact of age on postoperative complication rates among elderly patients with hip fracture: a retrospective matched study. J Anesth. 2018:32(3):452-6.

8. Anglen JO, Weinstein JN. Nail or plate fixation of intertrochanteric hip fractures: changing pattern of practice. A review of the American Board of Orthopaedic Surgery Database. J Bone Joint Surg Am. 2008;90(4):700-7.

9. Matre K, Havelin LI, Gjertsen JE, Vinje T, Espehaug B, Fevang JM. Sliding hip screw versus $I M$ nail in reverse oblique trochanteric and subtrochanteric fractures. A study of 2716 patients in the Norwegian hip fracture register. Injury. 2013;44(6):735-42.

10. Uzoigwe CE, Burnand $\mathrm{HG}$, Cheesman $\mathrm{CL}$, Aghedo DO, Faizi M, Middleton RG. Early and ultra-early surgery in hip fracture patients improves survival. Injury. 2013;44(6):726-9.

11. Colais P, Di Martino M, Fusco D, Perucci CA, Davoli M. The effect of early surgery after hip fracture on 1-year mortality. BMC Geriatr. 2015;15:141.

12. Aqil A, Hossain F, Sheikh $H$, Aderinto J, Whitwell G, Kapoor H. Achieving hip fracture surgery within 36 hours: an investigation of risk factors to surgical delay and recommendations for practice. J Orthop Traumatol. 2016;17(3): 207-13

13. Lizaur-Utrilla A, Martinez-Mendez D, Collados-Maestre I, Miralles-Munoz FA, Marco-Gomez L, Lopez-Prats FA. Early surgery within 2 days for hip fracture is not reliable as healthcare quality indicator. Injury. 2016;47(7):1530-5.

14. Bergdahl C, Ekholm C, Wennergren D, Nilsson F, Moller M. Epidemiology and patho-anatomical pattern of 2,011 humeral fractures: data from the Swedish fracture register. BMC Musculoskelet Disord. 2016;17:159.

15. Kihlstrom C, Moller M, Lonn K, Wolf O. Clavicle fractures: epidemiology, classification and treatment of 2422 fractures in the Swedish fracture register; an observational study. BMC Musculoskelet Disord. 2017;18(1):82. 
16. Müller ME, Nazarian, S., Koch, P. and Schatzker, J. (1990) The comprehensive classification of fractures of long bones/AO classification of fractures. SpringerVerlag, Berlin, Heidelberg. https://doi.org/10.1007/978-3-642-61261-9.

17. Mangram A, Moeser P, Corneille MG, Prokuski LJ, Zhou N, Sohn J, et al. Geriatric trauma hip fractures: is there a difference in outcomes based on fracture patterns? World J Emerg Surg: WJES. 2014;9(1):59.

18. Diaz AR, Navas PZ. Risk factors for trochanteric and femoral neck fracture. Rev Esp Cir Ortop Traumatol. 2018;62(2):134-41.

19. Carow J, Carow JB, Coburn M, Kim BS, Bucking B, Bliemel C, et al. Mortality and cardiorespiratory complications in trochanteric femoral fractures: a ten year retrospective analysis. Int Orthop. 2017;41(11):2371-80.

20. Chehade MJ, Carbone T, Awwad D, Taylor A, Wildenauer C, Ramasamy B, et al. Influence of fracture stability on early patient mortality and reoperation after Pertrochanteric and intertrochanteric hip fractures. J Orthop Trauma. 2015;29(12):538-43.

21. Buecking B, Bliemel C, Struewer J, Eschbach D, Ruchholtz S, Muller T. Use of the Gamma3 nail in a teaching hospital for trochanteric fractures: mechanical complications, functional outcomes, and quality of life. BMC research notes. 2012:5:651.

22. Pueyo-Sanchez MJ, Larrosa M, Suris X, Casado E, Auleda J, Fuste J, et al. Secular trend in the incidence of hip fracture in Catalonia, Spain, 2003-2014. Age Ageing. 2017;46(2):324-8.

23. Gronskag AB, Forsmo S, Romundstad P, Langhammer A, Schei B. Incidence and seasonal variation in hip fracture incidence among elderly women in Norway. The HUNT study. Bone. 2010;46(5):1294-8.

24. Schneider K, Oh JK, Zderic I, Stoffel K, Richards RG, Wolf S, et al. What is the underlying mechanism for the failure mode observed in the proximal femoral locking compression plate? A biomechanical study. Injury. 2015; 46(8):1483-90.

25. Tucker A, Donnelly KJ, Rowan C, McDonald S, Foster AP. Is the best plate a nail? A review of 3230 unstable intertrochanteric fractures of the proximal femur. J Orthop Trauma. 2018:32(2):53-60.

26. Zhu Q, Xu X, Yang X, Chen X, Wang L, Liu C, et al. Intramedullary nails versus sliding hip screws for AO/OTA 31-A2 trochanteric fractures in adults: a meta-analysis. Int J Surg. 2017:43:67-74.

27. Vermesan D, Prejbeanu R, Poenaru DV, Petrescu H, Apostol E, Inchingolo F, et al. Do intramedullary implants improve survival in elderly patients with trochanteric fractures? A retrospective study. La Clinica terapeutica. 2015 166(3):e140-5.

28. Hsu CE, Shih CM, Wang CC, Huang KC. Lateral femoral wall thickness. A reliable predictor of post-operative lateral wall fracture in intertrochanteric fractures. Bone Joint J. 2013;95-b(8):1134-8.

29. Mittal R, Banerjee S. Proximal femoral fractures: principles of management and review of literature. J Clin Orthop Trauma. 2012;3(1):15-23.

30. Haidukewych GJ. Intertrochanteric fractures: ten tips to improve results. J Bone Joint Surg Am. 2009;91(3):712-9.

31. Parker MJ, Handoll HH. Gamma and other cephalocondylic intramedullary nails versus extramedullary implants for extracapsular hip fractures in adults. Cochrane Database Syst Rev. 2010;9:Cd000093.

32. Kannegaard PN, van der Mark S, Eiken P, Abrahamsen B. Excess mortality in men compared with women following a hip fracture. National analysis of comedications, comorbidity and survival. Age Ageing. 2010;39(2):203-9.

33. Haentjens P, Magaziner J, Colon-Emeric CS, Vanderschueren D, Milisen K, Velkeniers B, et al. Meta-analysis: excess mortality after hip fracture among older women and men. Ann Intern Med. 2010;152(6):380-90.

34. Moja L, Piatti A, Pecoraro V, Ricci C, Virgili G, Salanti G, et al. Timing matters in hip fracture surgery: patients operated within 48 hours have better outcomes. A meta-analysis and meta-regression of over 190,000 patients. PLoS One. 2012:7(10):e46175.

35. Siegmeth AW, Gurusamy K, Parker MJ. Delay to surgery prolongs hospital stay in patients with fractures of the proximal femur. J Bone Joint Surg $\mathrm{Br}$ Vol. 2005;87(8):1123-6.

36. Lizaur-Utrilla A, Gonzalez-Navarro B, Vizcaya-Moreno MF, Miralles Munoz FA, Gonzalez-Parreno S, Lopez-Prats FA. Reasons for delaying surgery following hip fractures and its impact on one year mortality. Int Orthop. 2018.

37. Rashid RH, Zubairi AJ, Slote MU, Noordin S. Hip fracture surgery: does time of the day matter? A case-controlled study. Int J Surg. 2013;11(9):923-5.

38. Switzer JA, Bennett RE, Wright DM, Vang S, Anderson CP, Vlasak AJ, et al. Surgical time of day does not affect outcome following hip fracture fixation. Geriatr Orthop Surg Rehabil. 2013:4(4):109-16.
39. Wennergren D, Ekholm C, Sundfeldt M, Karlsson J, Bhandari M, Moller M High reliability in classification of tibia fractures in the Swedish fracture register. Injury. 2016;47(2):478-82.

40. Juto H, Gartner Nilsson M, Moller M, Wennergren D, Morberg P. Evaluating non-responders of a survey in the Swedish fracture register: no indication of different functional result. BMC Musculoskelet Disord. 2017;18(1):278

41. Wennergren D, Stjernstrom S, Moller M, Sundfeldt M, Ekholm C. Validity of humerus fracture classification in the Swedish fracture register. BMC Musculoskelet Disord. 2017:18(1):251.
Ready to submit your research? Choose BMC and benefit from:

- fast, convenient online submission

- thorough peer review by experienced researchers in your field

- rapid publication on acceptance

- support for research data, including large and complex data types

- gold Open Access which fosters wider collaboration and increased citations

- maximum visibility for your research: over $100 \mathrm{M}$ website views per year

At $\mathrm{BMC}$, research is always in progress.

Learn more biomedcentral.com/submissions 